\title{
A new methodology for urban wind resource assessment
}

\author{
Teresa Simões, Ana Estanqueiro* \\ Laboratório Nacional de Energia e Geologia - LNEG, Estrada do Paço do Lumiar, 1649-038 Lisboa, Portugal
}

\section{A R T I C L E I N F O}

\section{Article history:}

Received 2 March 2015

Received in revised form

10 August 2015

Accepted 6 December 2015

Available online 24 December 2015

\section{Keywords:}

Urban wind

Resource assessment

Micro-generation

CFD

\begin{abstract}
A B S T R A C T
In the latest years the wind energy sector experienced an exponential growth all over the world. What started as a deployment of onshore projects, soon moved to offshore and, more recently to the urban environment within the context of smart cities and renewable micro-generation. However, urban wind projects using micro turbines do not have enough profit margins to enable the setup of comprehensive and expensive measurement campaigns, a standard procedure for the deployment of large wind parks. To respond to the wind assessment needs of the future smart cities a new and simple methodology for urban wind resource assessment was developed. This methodology is based on the construction of a surface involving a built area in order to estimate the wind potential by treating it as very complex orography. This is a straightforward methodology that allows estimating the sustainable urban wind potential, being suitable to map the urban wind resource in large areas. The methodology was applied to a case study and the results enabled the wind potential assessment of a large urban area being consistent with experimental data obtained in the case study area, with maximum deviations of the order of $10 \%$ (mean wind speed) and 20\% (power density).
\end{abstract}

() 2015 Elsevier Ltd. All rights reserved.

\section{Introduction}

Urban wind energy has a large potential to be explored in the context of smart cities, whether through the installation of small wind turbines in the domestic sector (building rooftops and surrounding areas), or integrated in the building envelope providing that they are designed with wind energy exploitation in mind [1]. The wind potential in urban areas is difficult to characterize due to the high impact of obstacles and structures on the atmospheric flow. Buildings often cause flow separation, wind speed reduction and high turbulence on the top and around buildings. Also, in economic terms, the high costs of wind measurements campaigns are an important barrier to the development of this sub-sector of wind energy. Other data sources may be used for the characterization of the wind flow in urban environment, such as databases and national and regional wind potential atlas. These solutions are usually based on the application of data from mesoscale models $\left(\mathrm{MM}^{1}\right.$ - Fifth Generation Mesoscale Model, WRF - Weather

Abbreviations: MM5, Fifth Generation Mesoscale Model; WRF, Weather Research and Forecasting; CFD, Computational Fluid Dynamics; U-DTM, Urban Digital Terrain Model; PD, Power Density.

* Corresponding author.

E-mail addresses: teresa.simoes@ineti.pt (T. Simões), ana.estanqueiro@ineti.pt (A. Estanqueiro).
Research and Forecasting) to standard microscale models (e.g. WASP - Wind Atlas Analysis and Application Program [2]) that despite their validity, are not adapted to these environments. In both methods, the wind potential is often overestimated [3].

The use of CFD (computational fluid dynamic) models to characterize the wind behavior around buildings is nowadays state of the art. Nevertheless, the application of these models is highly time consuming, in particular when one needs to model large areas to adequately assess the impact of structures on the wind flow. The complexity of the domain's geometry requires the use of powerful computers in order to obtain reliable results, and reinforces the non-suitability of most CFD programs to the study of large areas. In this context, a methodology was developed to characterize the urban wind potential, based on the construction of a surface involving the buildings' area, so that it can be treated as a very complex orography. This methodology considers the application of CFD models to small areas of a certain urban region, enabling the establishment of correction factors to the overall spatial distribution of the wind flow. In recent years the CFD sector has developed several commercial products, with some of them especially oriented to urban wind applications. In this particular case, the WindSim model [4] (referred subsequently as CFD-Complex) is used to model the surface of the buildings and the surrounding terrain (urban digital terrain model: U-DTM) and the Meteodyn model [5] (referred subsequently as CFD-Urban) is used to model 